\title{
THE OUTPUT OF THE HEART IN PATIENTS WITH ABNOR- MAL BLOOD PRESSURES
}

By C. SIDNEY BURWELL AND W. CARTER SMITH

(From the Medical Clinic, Vanderbilt University Hospital, Nashville)

(Received for publication September 18, 1928)

Heart failure is preceded by hypertension in a considerable percentage of cases. O'Hare, Calhoun and Altnow (1) have recently shown that many patients with heart failure of the type called "chronic myocarditis" or "myocardial insufficiency of unknown origin" have had high blood pressure in the past. In any attempt to analyze the effects of high systemic arterial pressure and to evaluate it as a factor in the causation of heart failure, it is desirable to have knowledge of the other dynamic factors known to be concerned in the work of the heart. The work of the heart is determined chiefly by its output of blood per minute, by the pressure in the pulmonary artery and in the aorta against which it pumps, and by the velocity imparted to the blood by the heart. In the absence of greatly increased output the velocity factor is small relative to the other two, although, as Evans (2) has shown, when large outputs are concerned it may be of major importance.

Blumgart and Weiss (3) have studied the velocity of blood flow in patients with arterial hypertension. They found that patients with hypertension who exhibited no evidence of circulatory disability could be divided into two groups: in one, the velocity of blood flow was within the limits of normal, in the other the velocity was retarded.

Cardiac output in patients with arterial hypertension has been studied by Plesch (4), by Liljestrand and Stenström (5), and by Hayasaka (6). Plesch's results in four cases showed on the average no definite variation in either direction. Liljestrand and Stenström made repeated observations of the cardiac outputs of five women suffering from increased blood pressure and chronic nephritis. They used the nitrous oxide method of Krogh and Lindhard (7) and found 
that the average cardiac output of these patients was increased 26 per cent above the average of a group of normal subjects. The basal metabolic rate was correspondingly on the average 17 per cent higher than in the control group. The highest outputs were in cases with moderately elevated pressures rather than in those with extremely high ones.

The work of Hayasaka, which was done by the triple-extrapolation method of Redfield, Bock, and Meakins (8), gave somewhat confusing results. He used the output per minute per square meter of body surface as the standard of comparison, a value which Burwell and Robinson (9) have shown to be an uncertain one, and found the cardiac output increased in "benign hypertension" and in "malignant hypertension with nephritis," but unchanged in cases with "secondary contracted kidney." No data concerning variations in metabolic rate are given, but the experiments were performed under standard conditions. The author is of the opinion that hypertension in these cases may be dependent upon the elevated cardiac output, but he also points out that increased blood pressure is not always accompanied by increase in cardiac output.

\section{METHODS}

The observations here reported were made by the method of Field, Bock, Gildea and Lathrop (10) with careful attention to the constancy of "standard basal" conditions as described in previous publications (11). In each case, observations were made only after several days of rest in hospital had led to the establishment of a relatively fixed level of bood pressure. Whenever possible, more than one observation was made on each subject. To emphasize the ease with which this method may be applied to patients untrained in respiratory methods and as evidence for the reliability of the results obtained there is presented in table 1 a record of all the differences in arterial and venous carbon dioxide tension observed in these experiments. It will be noted that in each experiment the arterio-venous differences agree satisactorily, usually within $1 \mathrm{~mm}$. and that the maximum variation is $1.7 \mathrm{~mm}$.

Five patients with arterial hypertension were studied, three men and two women. The systolic pressures ranged between $175 \mathrm{~mm}$. and 
$225 \mathrm{~mm}$. mercury and the diastolic between $110 \mathrm{~mm}$. and $140 \mathrm{~mm}$. Although we attempted to select relatively uncomplicated cases all of the patients, as may be seen from the appended clinical summaries, showed evidence of more or less arteriosclerosis and several of them had undoubted chronic nephritis. One patient (case 5) had had a partial thyroidectomy four months before our study was made, and at the time of observation had a slightly elevated basal metabolic rate. No patient had evidence of congestive heart failure at the time of observation and only one (case 3 ) had a history suggesting its presence previously. All patients in the group showed definite evidence of cardiac enlargement in the teleoroentgenogram or by per-

TABLE 1

Arterio-venous differences in carbon dioxide tension (millimeters of mercury)

\begin{tabular}{c|c|c|c|c|c|c|c|c|c|c|c|c|c|c}
\hline Subject number..... & 1 & 2 & 2 & 3 & 3 & 4 & 4 & 5 & 5 & 6 & 7 & 7 & 8 & 9 \\
\hline Experiment number. & 1 & 2 & 3 & 4 & 5 & 6 & 7 & 8 & 9 & 10 & 11 & 12 & 13 & 14 \\
\hline 1 & 11.1 & 7.8 & 6.3 & 8.1 & 9.8 & 9.9 & 8.2 & 8.6 & 7.4 & 7.6 & 7.8 & 6.8 & 8.0 & 11.9 \\
2 & 10.3 & 7.4 & 6.9 & 7.9 & 9.8 & 8.4 & 9.9 & 8.4 & 7.3 & 7.3 & 7.7 & 8.3 & 8.0 & 11.7 \\
3 & 11.5 & 6.8 & 7.1 & 8.7 & 8.9 & 9.2 & 9.3 & 8.7 & 7.2 & 7.5 & 7.2 & 7.1 & 7.9 & 10.9 \\
4 & & & & 7.5 & 9.6 & 8.6 & 8.6 & 8.3 & 7.4 & 7.4 & & & & 11.5 \\
5 & & & & & & 8.8 & 9.0 & 8.3 & & & & & & \\
\hline Average...... & 10.9 & 7.3 & 6.8 & 8.1 & 9.5 & 8.9 & 9.0 & 8.5 & 7.3 & 7.5 & 7.6 & 7.4 & 8.0 & 11.4 \\
\hline
\end{tabular}

cussion. In four subjects a second estimation of cardiac output was made after an interval of one or more days.

Similar observations were carried out upon four men exhibiting systolic blood pressures of from $65 \mathrm{~mm}$. to $95 \mathrm{~mm}$. of mercury and diastolic pressures ranging from $55 \mathrm{~mm}$. to $70 \mathrm{~mm}$. Of these, one was a case of rapidly progressive Addison's disease, in which the diagnosis was subsequently confirmed by autopsy. To within 48 hours of our observation he had been receiving frequent injections of adrenalin and also whole dried adrenal gland by mouth. Another subject was a young man suffering from tuberculosis of the lungs and cecum and probably Addison's disease. Two measurements were made of this patient's cardiac output. Of the two other subjects, Cases 8 and 9, one was a member of the hospital staff and the other a medical student, 
both apparently quite normal, but having low systolic blood pressure under the imposed conditions of fasting and rest.

For convenience in comparison certain average values are calculated. In order to avoid distortion because some patients have two and some only one set of figures, the averages are obtained by calculating first the average values for each subject and then computing the average of these figures.

\section{RESULTS}

The results of the studies are given in table 2. The cardiac output of all the subjects in both groups falls within the limits seen in normal healthy people when the blood pressures are within the usual zone. The averages of the cardiac outputs in the two groups are almost identical and the average cardiac output per minute per kilogram of body weight and the average output of the heart per beat are of the same general order. The absence of variation is striking when it is observed that the average pulse pressure in the hypertensive group is $85 \mathrm{~mm}$. as against $26 \mathrm{~mm}$. in the hypotensive group.

The basal metabolic rate is on the whole somewhat higher in the group with high pressures than in the group with low. This is partly explicable on the score of the elevated rate of subjects 4 and 5, on the one hand, and the characteristically low rate of the patient with Addison's disease, on the other. The cardiac output per $100 \mathrm{cc}$. oxygen absorbed is, however, of the same order in the two groups. The pulse rates in both groups with the exception of those of the two normal men are slightly above the low level usually attained under satisfactory "basal" conditions, and the average rate is higher in the hypertensive cases, just as is the metabolic rate. The arterio-venous differences do not differ significantly in the two groups.

\section{DISCUSSION}

These observations demonstrate that under conditions of bodily rest patients with arterial hypertension have no significant increase in the cardiac output. The hypothesis that hypertension in general is secondary to an increased output is thus not tenable. An admissible objection to this conclusion is the possibility that the cardiac output was increased earlier in the history of these patients but that at the 


\begin{tabular}{|c|c|c|c|c|c|c|}
\hline & 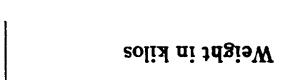 & & 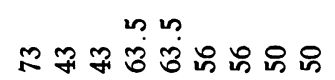 & in & そむせ & $\because 8$ \\
\hline & 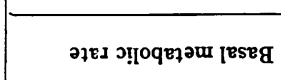 & $\$$ & 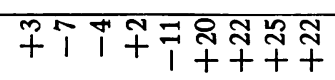 & $\bar{f}$ & $\underset{1}{\infty}+\frac{n}{+} \rightarrow$ & $\frac{1}{1}$ \\
\hline & 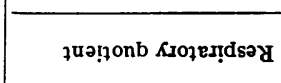 & & 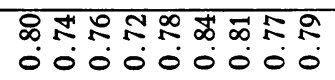 & & 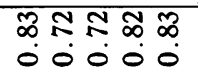 & \\
\hline & әре] әs[nd & 5.to & 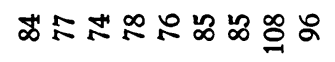 & あ & 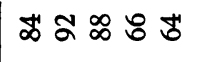 & 운 \\
\hline & 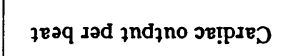 & ن & 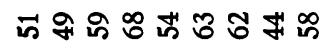 & 웅 & 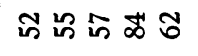 & 范 \\
\hline 窎 & 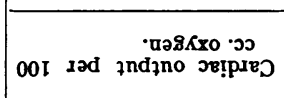 & ن & 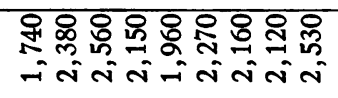 & $\begin{array}{l}8 \\
\stackrel{8}{2} \\
i\end{array}$ & 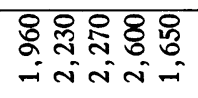 & $\begin{array}{l}n \\
\substack{0 \\
0} \\
i\end{array}$ \\
\hline 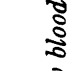 & 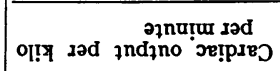 & ن & 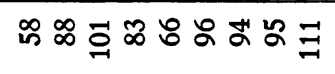 & 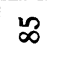 & 尺ジすのチ & $\Re$ \\
\hline$\frac{3^{2}}{3}$ & 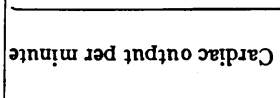 & ن & 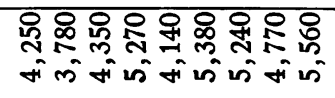 & 8 & 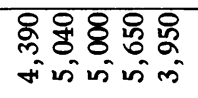 & in \\
\hline 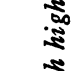 & -u!̣u səd әp!̣xo!̣p uoqIe & ن & 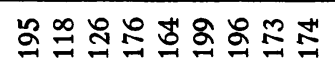 & & 엄 & \\
\hline 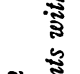 & 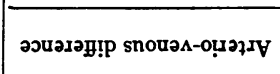 & 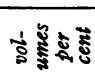 & 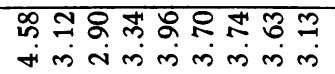 & $\begin{array}{l}n \\
\ddot{n} \\
\dot{m}\end{array}$ & 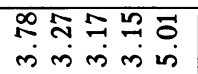 & $\stackrel{n}{n}$ \\
\hline हี & 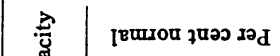 & & 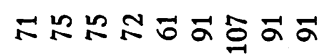 & & ஃ $\infty \infty \varnothing 8$ & \\
\hline $\begin{array}{c}-7 \\
2 \\
2\end{array}$ & 胥 & ن & 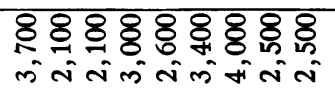 & & 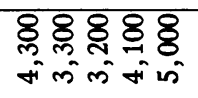 & \\
\hline 2 & əInssəנd əs[n $n_{d}$ & 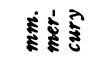 & 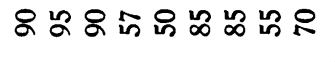 & $\infty$ & శ్రిల్ల & ז \\
\hline $\begin{array}{c}3 \\
3\end{array}$ & गฺ위ระ!: & ह & 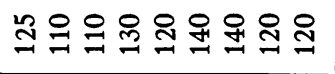 & & ำำำำㅇํㅇ & \\
\hline & 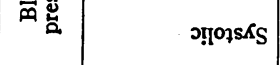 & 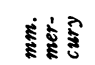 & 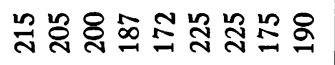 & & ทั & \\
\hline है & səquinu ₹ ұ & & $H N m+$ & $\vdots$ & 으ニ $\cong \pm$ & $\vdots$ \\
\hline & دəqưnu əseग & & $\pi n m$ & 雚 & $0 \sim \infty a$ & تّ \\
\hline & 㫕 & & 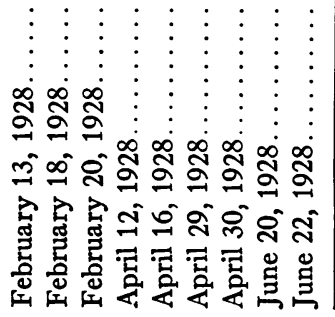 & 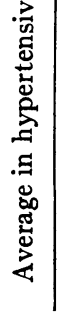 & 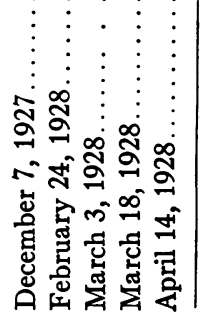 & 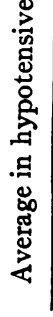 \\
\hline
\end{tabular}


time of observation they had reached a stage of the disease when the heart could no longer maintain so great an increase. Against the possibility of this it may be said that these were patients without signs or symptoms of heart failure and capable without distress of degrees of exertion certainly demanding greater cardiac output.

These observations show also that the increase in the work of the heart leading to its hypertrophy in patients with actual hypertension is due not to changes in velocity or cardiac output but to increase in resistance, unless exercise in hypertensive patients is accompanied by a disproportionate increase in output. Holman and Beck (12) from a comparison of the heart weights in two similar dogs, one of which had pulmonic stenosis and the other a large septal defect, infer that increased flow of blood through the heart is a more potent stimulus to hypertrophy and dilatation than increased peripheral resistance. The stimulus in our cases, however, was apparently increased resistance since no elevation of the cardiac output was observed.

A comparison of the hypertensive and hypotensive groups shows a striking lack of relationship between blood pressure and cardiac output. Here are patients with very high and very low systolic pressures, and with great variations in pulse pressure, but with nearly identical cardiac outputs. Blumgart and Weiss (3) pointed out the fact that hypertension does not necessarily imply any change in the velocity of blood flow. If increase in tension were necessarily followed by increase in cardiac output, or by increased velocity, the work of the heart would be still further increased to its further hurt. These observations must not be thought to show that hypertension and greatly increased cardiac output are never associated. They often are, as with the development of severe anemia in chronic nephritis with hypertension. And hypotension may, for example, be associated with distinctly diminished cardiac output in animals in shock as Blalock (13) has shown. The association of hypertension and increased output, or hypotension and decreased output, is accordingly not a necessary one.

These studies bear on the question of proportionality between pulse pressure and output per beat, a relation suggested by Erlanger and Hooker (14), who were fully aware of its limitations. Rosen and White (15) have recently brought evidence to show that the pulse 
pressure is directly proportional to the output per beat in consecutive observations in the same individual under conditions that produce essentially the same diastolic pressure and heart rate. Our experiments show a complete lack of proportionality in different individuals, a lack of correspondence due, as Wiggers (16) points out, to variations in vascular elasticity and tonicity, the viscosity of the blood, and other factors.

\section{SUMMARY}

In two groups of cases, one with systolic blood pressures of over $175 \mathrm{~mm}$. of mercury and one with systolic blood pressures of less than $95 \mathrm{~mm}$. of mercury, the total cardiac output per minute, the cardiar output per minute per kilogram of body weight and the cardiac output per $100 \mathrm{cc}$. of oxygen absorbed did not show significant differences. Pulse pressure and output per beat are not directly proportional in different individuals.

\section{PROTOCOLS}

1. F. H., a white male age 59 years, complained of headache, dizziness, impaired vision, weakness and impairment of memory for $\mathbf{5}$ years. He was known to have had an elevated blood pressure for 5 years, and nocturia seven to eight times for 1 year. On physical examination he was a plethoric individual, with advanced arterio-sclerosis and vascular retinitís. The cardiac dulness was $11.5 \mathrm{~cm}$. to the left and $4 \mathrm{~cm}$. to the right. The heart sounds were of good quality, no murmurs were heard. There was no pitting edema or other evidence of cardiac failure. There were albuminuria and cylindruria but no nitrogen retention.

The diagnosis was hypertension; arterio-sclerosis; chronic nephritis.

2. E. T., a colored woman of 55 years, had palpitation of the heart, weakness, and dyspnea on exertion for five years. There had been some precordial pain during one year. Examination showed a small, fairly well nourished colored woman. The eyegrounds showed vascular retinitis with retinal hemorrhages. The cardiac dulness was $9.0 \mathrm{~cm}$. to the left and $4.0 \mathrm{~cm}$. to the right and the supracardiac dulness was $5.8 \mathrm{~cm}$. wide. There were no evidences of cardiac failure, no anemia, and no evidence of nephritis.

The diagnosis was arterio-sclerosis, hypertension.

3. E. C., a colored male aged 36 years, complained of frequent attacks of palpitation of the heart for 14 months and some nocturnal dyspnea for 10 years. 
He had a primary syphilitic lesion 17 years ago. On physical examination he was well nourished and developed. Examination of the eyegrounds showed an early arteriosclerosis. The teleoroentgenogram of the heart showed it to be $10.3 \mathrm{~cm}$. to the left, $3.7 \mathrm{~cm}$. to the right, and the aortic shadow was $6.4 \mathrm{~cm}$. in diameter. The heart sounds were of good quality, there was a soft systolic murmur at the apex but no evidence of cardiac failure. There was very little peripheral sclerosis and no evidence of renal disease. The blood Wasserman was positive.

The diagnosis was hypertension, early vascular disease, syphilis.

4. A. J., a white male, aged 41 years, was known to have had hypertension and chronic nephritis for two and a half years. Headache was the most persistant and severe symptom. Examination showed a small, fairly well nourished man with no evidence of cardiac failure but with marked peripheral arterial sclerosis and eyeground changes. A seven foot plate of the heart showed it to be $8.5 \mathrm{~cm}$. to the left, $3.6 \mathrm{~cm}$. to the right, and the aortic shadow was $6.5 \mathrm{~cm}$. The heart sounds were of poor quality, but there were no murmurs. The blood contained $41 \mathrm{mgm}$. of non-protein nitrogen per $100 \mathrm{cc}$., there was constant albuminuria, and the specific gravity of the urine was low and fixed. There was no anemia.

The diagnosis was chronic nephritis, hypertension, and arteriosclerosis.

5. F. B., a white female of 26 years, admitted with a history of thyrotoxicosis four months previous to this entry. Thyroidectomy was performed at this time, this was followed by improvement but the blood pressure, which was known to have been elevated for seven months, remained high. She developed palpitation of the heart and slight dyspnea on exertion. On physical examination she was rather poorly nourished but there were no definite signs of thyrotoxicosis. The cardiac dulness was $9.5 \mathrm{~cm}$. to the left. There was very little peripheral sclerosis, no evidence of renal impairment and no edema or other evidence of cardiac failure. The basal metabolic rates on successive days were 25 and 22 per cent above the calculated normal.

The diagnosis was hypertension, thyrotoxicosis (mild), early vascular disease.

6. F. B., a white male aged 40 years, complained of weakness and shortness of breath for one month previous to admission. The blood pressure was known to have been low for one month. On examination he was fairly well nourished and developed. There was some increased pigmentation of the exposed parts of the skin. There was no anemia. The cardiac dulness was not increased, the sounds were of poor quality, but there was no evidence of congestive heart failure. Adrenalin and extract of the whole gland produced no improvement and the patient died twenty days after admission. 'Post-mortem examination showed extreme atrophy of the adrenals.

The diagnosis was Addison's disease. 
7. C. B., a white male aged 24 years, complained of abdominal cramps and weakness for one year, with a loss of 36 pounds in 8 months. On examination the patient was found to be emaciated and rather pale with pigmentation suggesting Addison's disease. The cardiac dulness was $3 \mathrm{~cm}$. to the right, $6 \mathrm{~cm}$. to the left and the supra-cardiac dulness was $4 \mathrm{~cm}$. There were a few moist râles in both lung apices. There was some tenderness and resistance in the lower right quadrant of the abdomen. The red blood cells numbered 4,510,000 per $\mathrm{cm}$. The hemoglobin was 63 per cent.

The diagnosis was bilateral pulmonary tuberculosis, tuberculosis of the cecum, and Addison's disease (?).

8. W. G., was a normal, healthy medical student 23 years of age.

9. M. H., was a member of the hospital staff, 29 years of age and quite well.

\section{BIBLIOGRAPHY}

1. O'Hare, James P., Calhoun, A. W., and Altnow, Hugo O., J. Am. Med. Assoc., 1928, xc, 1436. The Etiology of Chronic Myocarditis.

2. Evans, C. Lovatt, J. Physiol., 1918, lii, 6. The Velocity Factor in Cardiac Work.

3. Blumgart, H. L., and Weiss, Soma, J. Clin. Invest., 1927, iv, 173. Studies on the Velocity of Blood Flow. IV. The Velocity of Blood Flow and Its Relation to Other Aspects of the Circulation in Patients with Arteriosclerosis and in Patients with Arterial Hypertension.

4. Plesch, Johann, Ztschr. f. Exper. Pathol. u. Therap., 1909, vi, 380. Hämodynamische Studien.

5. Liljestrand, G., and Stenström, N., Acta med. Skandinav., 1925, lxiii, 142. Clinical Studies on the Work of the Heart during Rest. III. Blood Flow in Cases of Increased Arterial Pressure with Observations on the Influence of Pregnancy on the Blood Flow.

6. Hayasaka, Enaji, Tohoku J. Exper. Med., 1927, ix, 401. On the Minute Volume of the Heart in Hypertension.

7. Krogh, A., and Lindhard, J., Skandinav. Archiv. f. Physiol., 1912, xxvii, 100. Measurements of the Blood Flow through the Lungs of Man.

8. Redfield, Alfred C., Bock, Arlie V., and Meakins, J. C., J. Physiol., 1922, lvii, 76. The Measurement of the Tension of Oxygen and Carbon Dioxide in the Blood of the Pulmonary Artery in Man.

9. Burwell, C. Sidney, and Robinson, G. Canby, J. Clin. Invest., 1924, i, 87. The Gaseous Content of the Blood and the Output of the Heart in Normal Resting Adults.

10. Field, H. Jr., Bock, A. V., Gildea, E. V., and Lathrop, F. L., J. Clin. Invest., 1924, $i, 65$. The Rate of the Circulation of the Blood in Normal Resting Individuals. 
11. Burwell, C. Sidney, Neighbors, DeWitt, and Regen, Eugene M., J. Clin. Invest., 1927, v, 125. The Effect of Digitalis upon the Output of the Heart in Normal Man.

12. Holman, Emile, and Beck, Claude S., J. Clin. Invest., 1926, iii, 283. The Physiological Response of the Circulatory System to Experimental Alterations. III. The Effect of Aortic and Pulmonic Stenoses.

13. Blalock, Alfred, Arch. Surg., 1927, xv, 762. Mechanism and Treatment of Experimental Shock. I. Shock Following Hemorrhage.

14. Erlanger, J., and Hooker, D. R., Johns Hopkins Hosp. Reports, 1904, xii, 145. An Experimental Study of Blood Pressure and of Pulse Pressure in Man.

16. Rosen, I. T., and White, H. L., Am. J. Physiol., 1926, Ixxviii, 168. The Relation of Pulse Pressure to Stroke Volume.

17. Wiggers, Carl J., Modern Aspects of the Circulation in Health and Disease, Philadelphia, 1923, 2nd ed. p. 366. 